\title{
Exploring the Medical Benefits of Sudanese Medicinal Plants as a Practical Element in Sustainable Development
}

\author{
Ashraf Abdalla, Peter Fischer and Tracey Bradshaw \\ University of Nottingham, $U K$
}

\begin{abstract}
This paper illustrates the significance of natural products and the role that it plays as indispensable source of drugs. Drug discovery and development programmes are in critical situation worldwide due to the decrease of the number of new introduced medicines in the market. It is described how Sudan, which is endowed with huge recourses of medicinal plants and is witnessing The Agricultural Revolution, can contribute to the drug discovery programmes by utilization of its plants; all which could bring benefit not to Sudan people and health sector only, but also regionally and worldwide.
\end{abstract}

\section{Introduction}

Since the dawn of time, mankind started to recognize and exploit their surroundings, and tried to discover the secrets of nature. Mankind found unlimited uses for plants: food, beverages, shelter, clothes, ornaments, and tools. Disease was, and still is, man's enemy number one, so it made sense to focus on plants as a reliable, safe, effective and readily available source of medication. The use of plants as remedies dates back to the ancient Pharaonic Egyptians era (3000 B.C.), where evidence of plants was seen in graves together with the mummified bodies. In China (2700 B.C.), the first medicinal plants book appeared, which was the basis for books that followed such as 'The Great Herbal'. In the Romanic era, Materia Medica appeared as a reference book, which included 958 plants with description of their uses (Saad et al., 1988). This paper describes the importance and some of the problems facing medicinal plants and traditional medicine worldwide and in the Sudan, and how Sudan can play role in the universal process of drug discovery.

The importance of traditional medicine as a source of primary health care (PHC) was first officially recognized by the World Health Organization (WHO) in the primary health care declaration of Alma Ata (1978) and has been globally addressed since (1976) by the Traditional Medicine Programme of the WHO (Rukangira, 2001).

Traditional medicine, in one form or another, is widespread throughout the world. As its name implies, it is part of the tradition of each country, where it is handed down from generation to generation. Its acceptance by a population is largely conditioned by cultural factors and much of traditional medicine is therefore not readily transferred from one culture to another (Akerele, 1991).

The Traditional Medicine programme of the WHO defined traditional medicine as: "The sum total of all the knowledge and practices, whether explicable or not, used in diagnosis, prevention and elimination of physical, mental or social imbalance and relying exclusively on practical experience and observation handed down from generation to generation, whether verbally or in writing" (Rukangira, 2001). Herbal medicine is also defined as: "A plant derived material or preparation with therapeutic or other human health benefits which contains either raw or processed ingredients from one or more plants. In some traditions, materials of inorganic or animal origin may also be present" (WHO, 1993).

C) SPRU and WASD 2009 
WHO has described traditional medicine as "One of the surest means to achieve total health care coverage of the world's population" (Rukangira, 2001), and estimated that $80 \%$ of the population of developing countries relies on traditional medicines, mostly plant drugs, for their primary health care needs. Also modern pharmacopoeias still contain at least $25 \%$ drugs derived from plants and many others which are synthetic analogues built on prototype compounds isolated from plants (Schmincke, 1997). The WHO prepared a list of 20000 medicinal plants used worldwide and indicated that 4000 drugs from plant origin are used in a wide range worldwide.

What is significant is the growing recognition from the industrialized world, that these socalled traditional values are valid for all people, responding to the environmental and ecological deterioration that threatens health and development everywhere (Akerele, 1991).

A recent review by the National Cancer Institute (NCI) emphasized that natural products still play a dominant role in the discovery of leads for the development of drugs for the treatment of human diseases. It is argued that these further serve to illustrate the inspiration provided by nature to receptive organic chemists in devising ingenious syntheses of structural mimics to compete with nature's longstanding substrates. Even discounting these categories, the continuing and overwhelming contribution of natural products to the expansion of the chemotherapeutic armamentarium is clearly evident, and much of nature's "treasure trove of small molecules" remains to be explored. And so the exploration of nature is strongly advocated to be expanded, not to be decreased, as a source of novel active agents that may serve as the leads and scaffolds for elaboration into desperately needed efficacious drugs for a multitude of disease indications. (Newman and Cragg, 2007).

This particularly is evident in the areas of cancer and infectious diseases, where over $60 \%$ and $75 \%$ of these drugs, respectively, were shown to be of natural origin. (Newman et al., 2003).

\section{Traditional Medicine in the Sudan}

The Sudan, the largest African country, is an ethnic mosaic of about 700 tribes, many of which are traditionally endogamic. Diet is based on vegetable foods, with meat and animal fat accounting for less than $25 \%$ of the dietary energy supply. (Awadelkarim et al., 2007). The broad ethnic and climatic diversity of the Sudan makes it in many ways a microcosm of Africa (Hamad, 2006). The flora of the Sudan consists of more than 3137 species of flowering plants belonging to 170 families and 1280 genera. Of these: only 278 species, 210 genera and 72 families have already been identified as medicinal, culinary and aromatic plants (MCA). Research is expected to identify others. (Elkhalifa, 2003).

About $75 \%$ of the population of the Sudan uses medicinal plants as home remedies and for their health and body care. The use of medicinal plants, such as fruits of tabaldi (Adansonia digitata: used as antidiarrheal), tamarind (Tamarindus indica: used as laxative and for Malaria), goddaim (Grewia tenx: used for treatment of anaemia) and roselle (Hibiscus sabdariffa: used as antihypertensive and for coughs) is wide spread all over the Sudan.

The Medicinal and Aromatic Plants Research Institute "MAPRI", in the Sudan, screened approximately 211 species for their antimicrobial activity, 100 species for their molluscicidal activity, 20 species for their anthelmintic activity, 20 species were pharmacologically studied, 60 species were phytochemically studied and 35 species were studied for improvement of productiv- 
Fig. 1 All new chemical entities, 01/1981-06/2006, by source $(N)$ 1184)

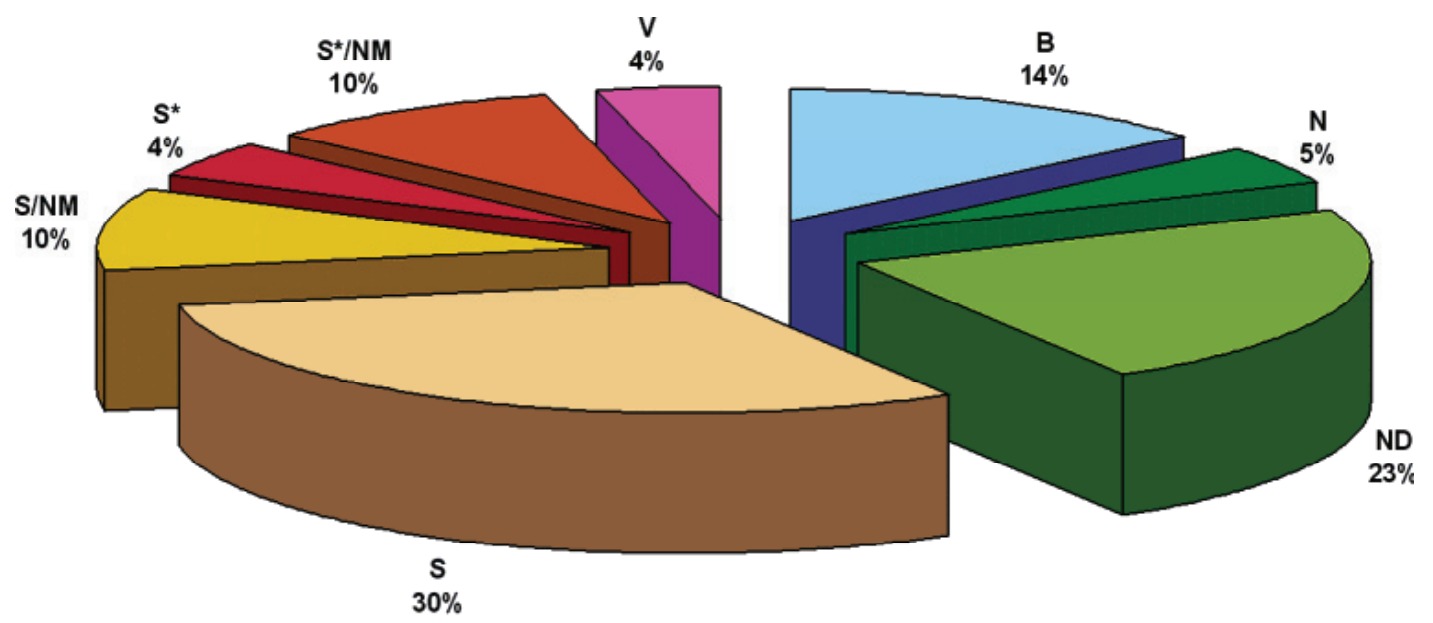

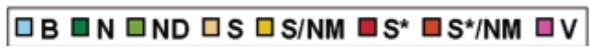

Fig. 2 All available anticancer drugs, 1940s-06/2006, by source (N) 175)
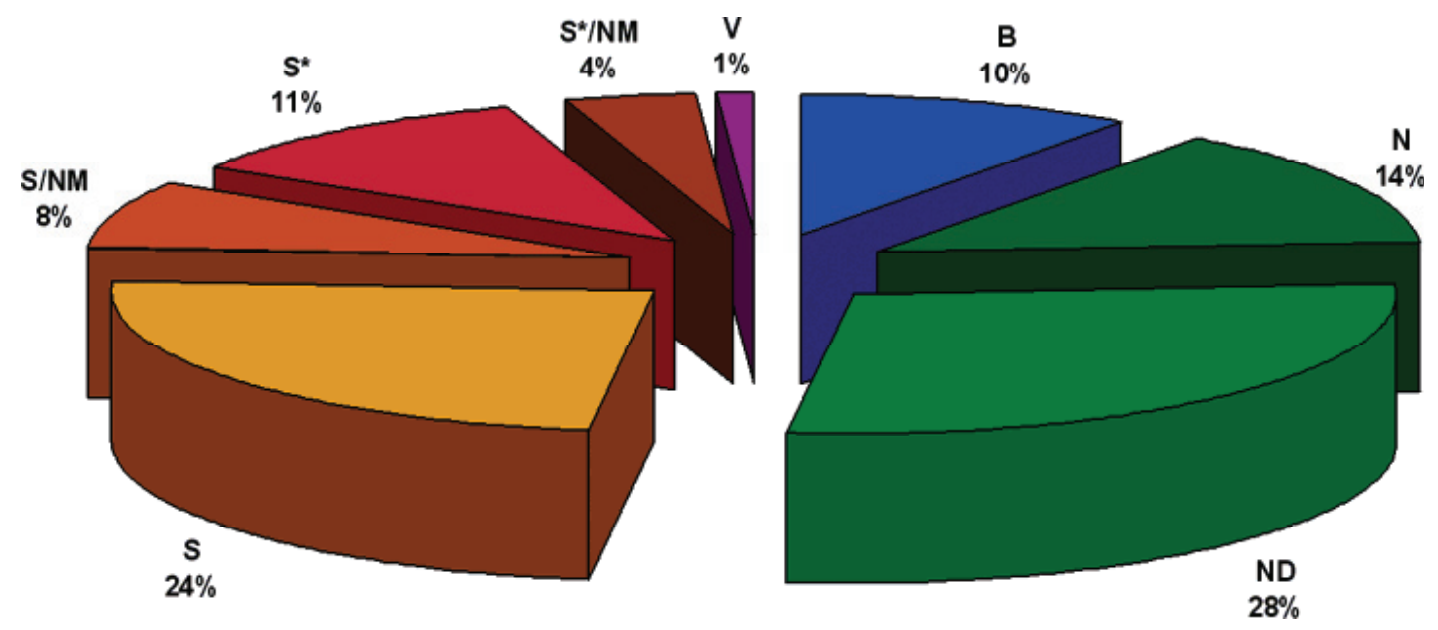

$\square B \square N \square N D \square S \square S / N M \square S^{*} \square S^{*} / N M \square V$

"B": Biological;

"N": Natural product;

"ND": Derived from a natural product;

"S": Totally synthetic drug;

"S/NM": Synthetic drug/Natural mimic;

"S*": Made by total synthesis;

"S*/NM": Total synthesis/Natural mimic and

"V": Vaccine.

(Source: Newman and Cragg, 2007). 
ity. Thus it is obvious that huge efforts must be made if the Sudanese flora is to be explored more comperhensively.

\section{Problems Facing Drug Discovery and Development Programmes}

The costs of drug discovery and development increase all the time, but there is a decrease in the number of new medicines introduced to the world market. Efforts are being made to improve the efficiency of the drug discovery process by using high through-put chemistry and screening technologies. This raises questions about whether natural products have any place in modern drug discovery.

\subsection{Developing countries}

In developing countries, where there are huge resources of medicinal plants; most of the indigenous flora has not been fully screened or even remains untouched. Difficulties begin with lack of research funds to support plant collection trips and research programmes, lack of well equipped laboratories and sufficient training of research staff; all of which help the early stopping of projects.

\subsection{Developed countries}

Natural products are unattractive to many drug discovery companies because of perceived difficulties relating to the complexities of natural product chemistry, and the access and supply of natural products. The technical difficulties relating to isolation and structural elucidation of bioactive natural products are being solved by contributions from many different natural product researchers, and the use of modern separation and structural elucidation tools.

With regard to accessing biodiversity from developing countries, much of the political discussion appears to focus on exploitation of traditional ethnobotanical knowledge, without considering the interest in natural products for random screening. It might be helpful if the two issues, indigenous rights and random screening, could be debated separately. However, many of the groups working on natural products are based in universities and research institutes throughout the world, and they are not very familiar with or well adapted to the molecular trends in drug discovery. Ways to improve communication between the practitioners of molecular drug discovery and natural products researchers would be helpful so that the chemical diversity that exists in nature is not lost to drug discovery (Harvey, 1999).

\section{How the Sudan can Play a Significant Role}

The Sudan is endowed with a rich medicinal flora scattered all over the ecological zones, which varies from complete desert in the north, to semi-desert with rainfall of varying intensity and duration, passing into a continental equatorial type of climate with a considerable dry season. This flora can play a key factor in the economics of drug discovery and development programmes (DDDP) as a long-term resource for research and development (R\&D), which can be shared between different bodies in the Sudan like: The Ministry of Science and Technology represented in the Medicinal and Aromatic Plants Research Institute, the Ministry of Higher Education, the Ministry of Health and Directorate of Pharmacy, the Ministry of Agriculture and Forestry; and other parties in the developed world like renowned research centres, universities and companies, where the latter can provide equipment and expertise. 


\section{Recommendations}

To begin with, introduction of a database for all known Sudanese plants including the plants which have been investigated would be of great benefit to identify the plants of interest and to avoid repetition of work. Then it is rational to initiate a consortium of all the related bodies in the Sudan, to implement and run economy-effective drug discovery and development programmes (DDDP), and to address diseases of urgent medical need. A fund-raising unit within each programme will be crucial to establish local and outside contacts, and to help opening channels for cooperation between home organizations and other bodies outside which might have mutual interests.

\section{Acknowledgements}

I am grateful to my supervisors Professor Peter Fischer and Dr Tracey Bradshaw, The Islamic Development Bank, Jeddah (IDB) and the International Office, University of Nottingham.

\section{References}

Akerele, Olayiwola (1991) 'Medicinal Plants and Primary Health Care: An Agenda for Action'. Eastern Mediterranean Region Drugs Digest. 8:2,11-25.

Awadelkarim, K. D. Gitana Aceto, Serena Veschi, Ahmed Elhaj, Annalisa Morgano, Ahmed Abdalla Mohamedani, Elgaylani Abdalla Eltayeb, Dafaallah Abuidris, Mario Di Gioacchino, Pasquale Battista, Fabio Verginelli, Alessandro Cama, Nasr Eldin Elwali and Renato Mariani-Costantini (2007) 'BRCA1 and BRCA2 status in a Central Sudanese series of breast cancer patients: interactions with genetic, ethnic and reproductive factors' Breast Cancer Res Treat 102:189-199.

Newman, David J.; Cragg, Gordon M. and Snader, Kenneth M. (2003) 'Natural Products as Sources of New Drugs over the Period 1981-2002'. J. Nat. Prod, 66, 1022-1037.

Newman, David J. and Cragg, Gordon M. (2007) 'Natural Products as Sources of New Drugs over the Last 25 Years'. J. Nat. Prod., 70, 461-477.

Elkhalifa, M.Y. (2003) 'Women and Income Generating Activities and Conservation of Natural Resources: Medicinal, Culinary and Aromatic plants in the Sudan'. Sustainable Development Programme (SD), FAO Regional Office for the Near East.

Hamad, H. M. A. (2006) ‘Cancer initiatives in Sudan'. Annals of Oncology, Volume 17, Supplement 1, pp. viii32viii36 (1).

Harvey, A. (1999) 'Medicines from nature: are natural products still relevant to drug discovery?' Trends in Pharmacological Sciences, Volume 20, Issue 5, 1 May 1999, Pages 196-198.

Rukangira, Ernest (2001) 'The African herbal industry constrains and challenges'. The natural products and cosmeceuticals conference. Erboristeria Domani (Pub.).

Saad, SI.; Gadi, A. and Salih, A.M. (1988) Medicinal, aromatic and toxic plants in the Arab world. Dar Mesr for Publishing (Pub.). Arab Organization for Agricultural Development (AOAD). Khartoum, Sudan.

Schmincke, Karl Hermann (1997) 'Medicinal plants for forest conservation and health care: Non wood forest product (FAO)'. Vol.11. Rome, Italy.

WHO (1993) World Health Organization. Research guidelines for evaluating safety and efficacy of herbal medicines. Regional office for the Western Pacific. Manila, Philippines. 